\title{
La idea de naturaleza en Aristóteles
}

\author{
Anibal Campos Rodrigo \\ Departamento Académico de Filosofia
}

\section{Introducción}

El vasto pensamiento aristotélico, complejo y diverso, es un motivo tan atrayente por su vigor y su sistematicidad, cuando no también por las dificultades que presenta a la comprensión de lo que efectivamente sostuvo acerca de los diversos objetos de su investigación.

Por su vastedad y complicación, han tenido que ocuparse de su compresión personalidades que han hecho época al constituirse en especialistas del pensamiento aristotélico. Temáticas como la vida animal y vegetal, del alma, del cielo, de las ideas, de la fisica, tocadas por su indagación nos han llegado como una imperecedera muestra de la gran inquietud humana por conocer y explicar la existencia y el modo de existencia de las cosas.

De entre la espesura decese pensamiento aristotelico nos ha atraido de manera particular su concepción de la naturaleza que no salta a la vista, sino que más bien se nos aparece un tanto escondida, un tanto huidiza, un tanto incapturable. Encontramos una reflexión, un análisis que va de un punto en punto como si sostuviera «esta es la naturaleza», para luego sugerimos que «esa parecer ser» pero que uno seria» porque naturaleza es, y cuando parece que nos está dando su definición de la misma, nos sugiere que naturaleza es otra cosa distinta. Asl, pues, trataremos de hacer un seguimiento de sus sugerencias, fallidas, hasta presentar lo que nos parece su definición de naturaleza, a riesgo de que aún sin ubicar su efectiva concepción de naturaleza, maxime si tenemos ante nosotros la sugerencia de Ross que afirma que «La Fisica» se presenta como "La ciencia de la naturaleza" pero que no propone al comienzo ninguna explicación de lo que se entiende por naturalezas!.

- Ross, W. David. Aristoteles. Editorial Sudamericana, Buenos Aires, 1975, p.95. 
Para nuestro cometido, el dar con «la idea de naturaleza en Aristóteles», seguiremos la exposición de Aristóteles en su Fisica, en el estudio de Aristóteles hecho por David W. Ross, en la presentación de pensamiento físico de Aristóteles hecha por Jean Brun y de manera tangencial por las lineas agresivas contra Aristóteles de Theodor Gomperz en su obra Pensadores Griegos (I-II) y aunque no llegáramos con éxito a concluir el empeño, sin embargo quedará en el haber de uno el haberse adentrado en el conocimiento del complejo y rico razonamiento de la Cumbre Griega que fue Aristóteles.

\section{La Naturaleza segín los pre-aristotélicos}

Por la referencia que Aristóteles hace a pensadores anteriores parece que el empeño de establecer qué es la naturaleza fue una preocupación ya anterior al propio Aristóteles. Cabe recordar que los primeros filósofos y científicos griegos lo son por tratar de investigar el cosmo, por lo que fueron llamados cosmólogos o también fisiólogos dado que al Cosmos también lo nombraban con el

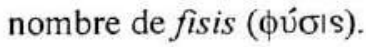

Tenemos, pues, que anteriormente a Aristóteles ya se ha tratado de decir qué es la naturaleza. Para unos, tal como lo recuerda éste, la naturaleza parecía ser: «aquello que en principio constituye cada cosa y que es esencia o por sí mismo informe; es decir, carente de forma $)^{2}$, y que pese a la modificación continua «impuesta por la forna y por efartese continuaria siendo la misma ( es decir la naturaleza). "Jorge Puccinelli Converso»

Según tal concepción, dice Aristóteles: «dicen unos filósofos que la naturaleza de las cosas es la tierra y otros que es el fuego, otros que es el aire, otros que es el agua, otros que son varios de esos elementos juntos, otros en fin, que son todos ellos juntos a la vez» ${ }^{4}$, "y que uno cualquiera de estos seres debia ser eterno, ya que ellos no poseían el cambio por sí mismos, mientras que los demás se producían y parecían infinito número de veces»s.

Aqui Aristóteles ha pasado revista a la concepción de naturaleza en sus antecesores. Donde para Thales la naturaleza sería el agua, para Heráclito el

\footnotetext{
2 Aristóteles. La Física (Tradución de A. Samaranch), Madrid, Editorial Aguilar, p. 588.

3 Ibid., p. 588.

4 Ibid., p. 588.

Ibid., p. 588 .
} 
fuego, para Anaxímenes el aire, para Empédocles la tierra, el agua, el aire, el fuego en conjunto, presentación que Aristóteles lo hace en su Fisica y en su metafisica.

Pero además Aristóteles vería que en la concepción de los filósofos anteriores a él está presenta la idea de que la naturaleza de las cosas, enfatiza Ross, es la presencia de «los contrarios como, primeros principios. Raro y denso, sólido y vacío, ser o no ser, alto y bajo, adelante y atrás, recto y curvon' ${ }^{6}$. La Naturaleza para los pre-aristotélicos serian, pues, los Ilamados y primeros principios, (o simplemente el principio), a partir de los cuales surgen las cosas, la variedad de las cosas en número y en cualidades; pero como sugiere Ross, Aristóteles no acepta que sean la naturaleza.

\section{Los determinantes de las cosas}

El mundo es un mundo poblado de cosas. ¿Pero cómo es que están allí las cosas?, ¿Siempre estuvieron alli las cosas tal y como están?; aquí Aristóteles va a señalar que están allí pero a partír de una composición. En tal composición interviene el «sujeto» que es aquello con que se hacen cosas, la semilla da plantadas, da animales; ese sujeto está como la materia-sujeto; es decir, como la materia con que se hacen cosas?

Ahora bien, dice Aristóteles: «llamo, en efecto, materia al primer sujeto de cada cosa y cada ser, a partir delcual sujeto, como de un elemento constitutivo, se hace o viene a ser algó y no de maneraaccidentalss ${ }^{\beta}$ En la composición de las cosas está la materia como su componente sin la cual no podría llegar a ser la cosa.

Pero si bien la materia es un componente imprescindible en el ser de las cosas, «sin embargo no es el único que concurre en la constitución de las mismas. Está, además, la forma o modo de estructura de una cosa por ejemplo un animal [que] es justamente aquello en virtud de lo cual ella se mueve, crece, cambia y llega al reposo al término de su movimiento. É inversamente, el poder de moverse, crecer y modificarse en un sentido determinado, constituye precisamente la forma o el carácter de cada cosas', dice Ross. Esto es, que en constitución

\footnotetext{
- Ross, W. David. op. cit., pp. 96-97.

- ARISTOTEles. OP. cil., p. 584.

8 lbid., p. 587. Cursiva mía [A.C.]

Ross, W. David. Op. rit., p. 102.
} 
concurre también la forma como por ejemplo en la estatua. Aquí encontramos bronce con una determinada organización estructura o figura, de donde la estatua ya no es solamente el bronce sino además una forma junto a la materia bronce; la estatua, la cosa estatua es estatua por estar en ella la materia (bronce) y la forma (figura determinada).

Mas Aristóteles indica que para que la estatua esté como tal estatua ha de entrar en su composición la finalidad y fin. La finalidad será: «aquello de cara a lo cual tiene lugar el movimiento o la causa final» ${ }^{10}$, a lo que debe llegar el destino, antes de que haya llegado efectivamente; la cosa estatua antes de ser la estatua real será la estatua causa final y la causa será la forma (estatua determinada) que ha de llegar a tener la materia bronce, en cuanto ésta es todavía la materia bronce; el fin será «el término»", el acabamiento, lo realizado, lo constituido (la estatua real). Y junto a estos constituidores de la cosa estatua ha de haber intermediado (o deberá intermediar) «una causa eficiente que obra teleológicamente $\rangle^{12}$ entre la materia bronce $y$ el fin (la forma alcanzada) guiada por la causa final.

Tales serian los constituidores de las cosas. De donde tenemos que las cosas que encontramos o que están allí, están alli a partir de su proceso de constitución. Proceso que se efectúa con la intervención de lo que llama Aristóteles las causas, cuya definición genérica da diciendo que causa es «aquello a partir de lo cual algo se hace y produce, de manera que permanece en el ser

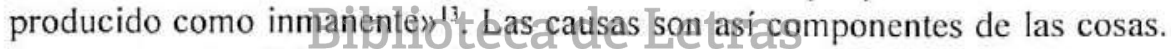
Las causas más básicas serían la causa materia y la causa forma. La materia en tanto que «es el medio de alcanzar este fin» ${ }^{4}$, ¿Cuál fin? la forma estatua, $v . g r$, como resume Ross, y la forma que se presenta como la causa final y fin; que exige la presencia de la causa eficiente que actualizará lo que está en potencia. Aristóteles insinúa a estas causas como la naturaleza ${ }^{15}$. Estas causas serían como principios a partir de los cuales se constituyen las cosas.

\footnotetext{
10 Aristóteles. OP. cit., p. 584.

"Ibíd, p. 590. (También Ross, Op. cit. 106). El fin será la cosa constituida

12 Ibid., p. 600. Cursiva mía [A.C].

13 Ibid., p. 591.

14 Ross, W. David. Op. cit., p. 106

15 Aristóteles. OP. cit., pp. 589, 590, 600.
} 


\section{LA NATURALEZA Y LAS COSAS}

En el libro segundo de su Fisica, Aristóteles trata de modo específico sobre la naturaleza, alli nos presenta su distinción de las cosas en cosas materiales y no materiales. Naturales, nos dice, son aquellas que «existen por naturalezan $^{16}$. Y no naturales aquellas que no existen por naturaleza, es decir, «por diversas causas $>{ }^{17}$ distintas de la natural y reza a pie de página la nota que dice de estas últimas que son: «la actividad práctica y poética del hombre $y$, por otra parte, la suerte y el azan ${ }^{18}$. Las cosas naturales, aquellas que están constituidas de modo natural; $y$ las no naturales que se han constituido por la intervención de la acción humana, del azar y la suerte, intervenciones accidentales a diferencia de la natural que sería, como sugiere Ross, "Esencial»"

\section{Sentidos en que se entiende naturaleza}

Aquí pasaremos revista a los sentidos en que, sugiere Aristóteles, se podria entender naturaleza. Asi, en un sentido, naturaleza se entendería como: "La materia-sujeto (componente) de cada ser, que posee en si misma el principio del movimiento y del cambio ${ }^{20}$, en donde en parte la naturaleza seria la materia. En otro sentido, naturaleza seria: (ula forma y la esencia que entra a formar parte de la definición. Pues igual que llamamos arte a lo que es conforme a las normas del arte y es artificioso o artificial, también se llama naturaleza a lo que es conforme a ella [a la naturaleza] yces natural.e En efecto, lo que potencialmente es carne o hueso no posee todavía sü propia naturaleza, mientras no haya recibido la forma, que integra su propia definición -es decir, la que empleamos para decir qué es la carne o qué es el hueso-»" en donde la naturaleza sería la forma.

En otro sentido: «La naturaleza podrfa ser la figura y la forma de aquellos seres, que tienen en sí mismos el principio del movimiento y del cambio, forma y figura que son separables a no ser por medio de la definición $>^{22}$, por

\footnotetext{
16 Ibld., p. 587.

${ }^{7}$ Hbid., p. 587 .

18 bid., p. 587.

19 Ross, W. David, p. 238.

20 Asustớteles, p. 588.

21 Ibld., p. 588-589. Cursiva mía [A.C.].

22 lbfd., p. 589.
} 
medio del pensamiento, en donde la naturaleza sería la forma y la figura de los seres naturales.

En otro sentido: «La naturaleza es una causa, y con toda exactitud, una causa eficiente que obra teleológicamente ${ }^{23}$, por lo cual la naturaleza como causa eficiente, según Aristóteles, es la que hace plantas de semillas, o también hijos de semen, etc.

En otro sentido: «La naturaleza es un fin y una causa final. Pues el fin de aquellas cosas, cuyo movimiento, por ser continuo, tiene algún fin es el término $y$ aquello de cara a lo cual tiene lugar el movimiento o la causa final $\gg{ }^{24}$.

\section{Naturaleza y elementos}

Tales presentaciones acerca de lo que puede ser la naturaleza están vinculadas a la existencia de las cosas y de modo estricto a las cosas que Aristóteles llama cosas naturales. Más, tales cosas naturales están constituidas con, de un modo o de otro, de lo que los primeros filósofos Ilamaron los elementos o principios como el agua, el fuego, el aire la tierra, las homeomerias, los átomos y vacio, el apeiron; pero Aristóteles al parecer no admite que tales elementos puedan ser considerados naturaleza, en el mejor de los casos la mayoría de ellos serian agrupados en lo que él Ilama la naturaleza materia-sujeto de cada còsa. Al parecer Aristóteles concede a la materia algún rango de naturaleza pero en tanto y en cuanto ella está associa dảert la cenposición dẹ una cosa; aspecto, este, que veremos adelante. "Jorge Puccinelli Converso»

\section{Naturaleza principio de...}

Lo que parece de manera explícita en Aristóteles acerca de qué cosa sea para él naturaleza lo podemos seguir en su diferenciación o clasificación de las cosas. Así, pues, existen cosas de dos grandes clases: 1) aquellas que no son naturales, dado que no existen por naturaleza sino por la acción humana, el azar y la suerte25.

Mientras que 2) la clase de las cosas naturales lo son por existir por naturaleza. Aquí naturaleza es concebida como un principio. ¿Y qué caracterizaría a

\footnotetext{
${ }^{23}$ Ibíd., p. 600 .

24 Ibid., p. 590.

${ }^{25}$ Ibid., p. 587.
} 
un principio?, Ross nos presenta la siguiente caracterización; dice del principio a de los principios: cosas, $y$

«1) Que no deben engendrarse uno de otro ni ser engendrados por atras

2) Que todas las otras cosas deben ser engendradas por ellos» ${ }^{25}$; que además deben ser finitos (reducidos) de lo contrario no podria el Ser ser conocido, pues sería incongnoscible, enfatiza Ross y agrega que los principios de Empédocles no son primarios, pues: «ninguno de los cuatro es primario, original, inmutable; todos se transforman unos en otros siguiendo un ciclow ${ }^{27}$; la naturaleza sería, pues un principio tal como lo anuncia Aristóteles cuando sostiene que las cosas naturales, son naturales por existir por naturaleza y que lo son por naturaleza al "poseer en sí mismas un principio de movimientos y de reposo»" ${ }^{28}$, y este principio de movimiento y reposo ha de estar en la cosa misma para que ella exista naturalmente, líneas adelante presenta otra expresión en la que indica que la naturaleza es un principio de movimiento o reposo que se encuentra inherentemente en las cosas naturales cuando expresa que: "Y sólo en la medida en que la naturaleza es un principio, la causa de que aquello que ella constituye primariamente se mueva y repose, por si mismo y no de forma accidental, es ella misma ${ }^{20}$. Asl, pues, la naturaleza es un principio de movimiento y de reposo y en la medida que las cosas lo tengan en sí mismas serán naturales, pero han de tenerlo esencialmente y no accidentalmente. Accidentalmente han de tenerlo aquellas cosas que se mueven o reposan por un principio de movimiento o reposo venido de fuera, de otros.

¿Qué cosas tienen naturaleza en sl esencialmente y qué cosas no y sólo accidentalmente? Dice Aristóteles: «Existen por naturaleza los animales y sus partes, las plantas y los cuerpos simples como la tierra, el fuego, el aire y el aguas ${ }^{30}$, respecto de las primeras; y que aquellos «seres que se hacen o devienen [donde] ninguno de ellos tiene en sí mismo el principio eficiente de su propia producción, sino que algunos seres lo tienen en otros y fuera de si mismos, como, por ejemplo, la casa y cualquier otro ser de los que son fruto de una manufactura o una fabricación; otros lo tienen en sí mismos, pero no de manera

\footnotetext{
26 Ross, W. David, p. 97.

27 lofd., p. 156.

21 ARstớthess, p. 587. Cursiva mía [A.C.]

7brd. p. 588.

to lbid., p. 587.

31 Jbid., p. 588.
} 
esencial y por si; y estas son todas aquellas cosas que accidentalmente pueden Ilegar a ser causas respecto de si mismas $)^{31}$, respecto de las segundas. La naturaleza, pues, en lo visto hasta el momento es un principio de movimiento y de reposo que tienen las cosas que son naturales o por naturaleza. Donde la naturaleza es «siempre una especie de sujeto y radica en éste» ${ }^{32}$.

\section{Naturaleza y movimiento}

Ahora bien este principio de movimiento, ¿como se presenta?, Aristóteles señala que en las cosas que lo poseen se presenta en «unas bajo la relación de lugar, [en] otras en el aspecto del aumento o la disminución, [en] otras bajo el aspecto de la alteración $)^{33}$. Aqui tendriamos que el principio de movimiento, que es la naturaleza, se presenta de varias maneras en las varias cosas naturales. Más adelante Aristóteles nos amplia su exposición del movimiento diciendo: «por ejemplo el movimiento de lo que es susceptible de alteración; y el movimiento de lo que puede aumentar, y no menos el de lo opuesto, es decir, de lo que es susceptible de disminución pues no hay un hombre común que abarque ambos procesos , es el aumento y la disminución; y el movimiento de aquello que posee la potencialidad de nacer y morir es el nacimiento y la muerte; finalmente, el movimiento de lo que es susceptible de traslación, es la misma traslación $\rangle^{34}$. Aquí podemos notar que el movimiento se presenta en clases de movimiento, donde además de movimiento es el movimiento de algo y no movimiento en si (sin algo, fuera de algo).

Hay un detalle interesante que Aristóteles nos presenta en relación a la naturaleza, el de que puederaber naturalezáy naturależas; éstas no exactamente iguales a la primera, cuando dice: "Se sigue de todo lo que precede, que la naturaleza primera, la naturaleza propiamente dicha, es la esencia de los seres, que tienen en sí y por sí mismos el principio de su movimiento. La materia no se llama en efecto naturaleza, sino porque es capaz de recibir en si este principio, y la generación, así como el crecimiento,... Y este principio del movimiento de las cosas naturales reside siempre en ellas ya sea en potencia, ya en acto ${ }^{35}$ esta naturaleza primera sería la naturaleza esencial.

Más, Aristóteles ha dicho que las cosas naturales lo son poseer intrinsecamente un principio de movimiento y reposo, así la naturaleza sería también prin-

12 Ibid., p. 588.

${ }^{33}$ Ibid., p. 587.

${ }^{34} \mathrm{Ibid}$. p. 602.Cursiva mía [A.C.]

${ }^{35}$ Ibid., Metafísica. Lima, Editorial Universo, 1972, Tomo 1, p. 99. Cursiva mía [A.C.] 
cipio de reposo, donde éste es «privación del movimiento, y no puede explicarse sino por el movimiento de que es privación $\aleph^{36}$; la naturaleza como principio de reposo no significa, nos resume Jean Brun, que sea «lo contrario sino la privación de movimiento; el reposo es el estado de lo que no se mueve ya, o de lo que no se mueve aún, o de lo que no puede moverse ${ }^{37}$ y de este modo se puede entender que hayan cuerpos o seres que «de no haber algo que lo impida (son) Ilevado(s) a su propio higar, unos hacia arriba, otros al contrario, hacia abajo» como indica Aristóteles ${ }^{38}$. Los seres naturales que se mueven o reposan por sí mismos lo hacen por poseer naturaleza, esto es, por poseer el principio de movimiento y de reposo esencialmente $y$ no por accidente.

\section{Naturaleza y generación}

La naturaleza concebida como principio de movimiento (y de reposo) que está presente como sujeto constituido de las cosas (o seres) que son naturales permite flegar a relacionar movimiento con generación, naturaleza con generación. Pues la misma palabra naturaleza ( $\phi \dot{\sigma L} \mathrm{~L}$ ) tal como nos alcanza el término Jean $B r u n^{39}$ viene de la palabra « $\phi u \omega »$ que significa "crecer»" que se asociaria con génesis.

Hagamos un seguimiento de los lugares en que encontramos puntos en su pensamiento para tal conexión.

Asi, allí donde nos dice Aristóteles kahora bien estas cosas existen por obra de la naturaleza, como afirmarian aún (= aún) los mismos que niegan su finalidad. Luego el existir y venir a ser con un fin determinado, es algo inherente a todos los que se hacen o existen por obra de la naturalezas ${ }^{41}$, podemos notar que naturaleza es concebida como aquello que hace que las cosas (determinadas cosas) lleguen a ser tales cosas, la naturaleza es presentada como fuerza generadora de acuerdo a un fin. Tal condición generadora es mencionada por Ross cuando cita a Aristóteles diciendo que: «..., por ejemplo, en la producción «por naturaleza) ( es decir, dice Ross, por el poder generador inherente al macho de

\footnotetext{
16 Brun. Jean. Aristóteles y el liceo. Buenos Aires, EUDEBA, 1963, p. 98.

" ló́d., p. 28.Cursiva mía [A.C.]

17 Aristóteles. Fisica Op. c'it, 615. Cursiva mía [A.C.]

19 Brun, Jean. Op. cit., 28.

to loid., p. 28.

" ARIstóteles. Fr.sir $a$ Op. rìt, 598. Cursiva mía [A.C.]
} 
seres monstruosos que no están de «acuerdo con la naturaleza» puesto que la forma suministrada por el macho no llega a dominar la materia provista por la hembra $)^{42}$, donde la naturaleza aparece componiendo al macho como una característica propia que le hace ser macho generador. $\mathrm{O}$ alli donde Aristóteles dice: «Queda, pues, claro que la naturaleza es una causa, y con toda exactitud, una causa eficiente que obra teleológicamente ${ }^{43}$, como causa eficiente, la naturaleza es, según Aristóteles, la que hace plantas de semillas, por ejemplo, o también hijos de semen, etc. y de este modo la naturaleza es principio de generamiento, generación, producción de una cosas a partir de elementos primarios.

La naturaleza, en la medida que es concebida como principio de movimiento, puede ser concebida como naturaleza generadora, generadora de movimiento, por ejemplo, por el cual pueden las semillas dar lugar a las plantas, los padres dar lugar a los hijos; la generación como desenvolvimiento, como la actualización de aquello que está en potencia. Pero aquí podríamos hallarnos con una serie de interrogantes acerca de la relación entre naturaleza y generación.

\section{La Naturaleza ¿es distinta de generación?}

Aqui trataremos de mostrar una reflexión acerca de problemas que rodean a la idea de naturaleza en Aristóteles.

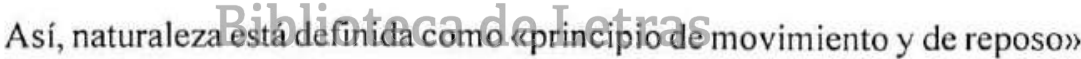
de las cosas en las quēceltacestá eséncililmentev Qrambién como "principio de movimiento y de cambio..... $\rangle^{44}$. $\mathrm{O}$ en otro modo como inherencia de las cosas cuando dice Aristóteles: "por otra parte, se llaman naturales o según la naturaleza todas las cosas dichas y todas aquellas que por sí mismas o esencialmente las constituyen o integran ${ }^{45}$, donde la naturaleza es inherente a algo (a las cosas naturales). La naturaleza es principio de movimiento, de generación, de reposo, de subir o bajar, etc; pero aquí las ciertas dificultades.

Si la naturaleza es principio de movimiento, se podrá decir luego que la naturaleza es igual o no al movimiento de que es principio. Si fuera igual al movimiento, y siendo el movimiento la naturaleza tendria que no existir por otro

\footnotetext{
${ }^{42}$ Ross, W. David. Op. cit., 114.

${ }^{43}$ ARISTÓteles. F/sica Op. cit, 600. Cursiva mía [A.C.]

44 Ibid., p. 601

45 Ibid., p. 588.
} 
porque de lo contrario ya no sería un principio primario sino derivado. Pero si fuera distinto del movimiento, entonces ¿qué sería exactamente la naturaleza?; algo distinto de que es principio.

Si la naturaleza es principio de reposo, sería igual al reposo y en consecuencia el reposo. Pero si esto fuera así la naturaleza como principio de movimiento desaparecería, y si esto sucediera ya no sería principio primario, pues reposo se define como "privación de movimiento», de donde siendo la naturaleza reposo ya no podría ser principio de movimiento. La naturaleza tendría que ser distinta de reposo y si esto es as ¿ ¿qué sería exactamente la naturaleza?; algo distinto del principio que es.

Ahora cuando Aristóteles dice, hablando del movimiento, que «el acto de aquello que existe en potencia, precisamente en cuanto es tal potencia, es el movimiento" ${ }^{46}$, nos presenta el acto como distinto de la potencia. Aquí podríamos decir: Qué la potencia és el estado de reposo y el acto el estado de movimiento. Pero si fuera la potencia, la naturaleza sería otra cosa distinta de movimiento, con lo cual no podria ser el principio del acto (o movimiento), dado que el reposo es la privación de movimiento; pero si es principio de movimiento (acto) y de reposo (potencia) y no es igual a ellos, entonces tiene una cjerta existencia autónoma; pero si esto es asi ¿qué exactamente serla la naturaleza?, aigo distinto de la potencia (o reposo) algo distinto del acto (o movimiento).

Si la naturaleza siendo principio: de movimiento, (y generación), y de reposo no es ni movimiento, ni la generación niel reposo iQué es, que no siendo aquello que provoca, o determina, sin embargo puede ser un principio, su punto de partida, su compositor?

Podriamos aqui sospechar que la naturaleza, principio de, sin ser aquello que, como tal principio, determina, no resultarla siendo otra cosa que ¿El primer motor? Quizás nuestras incertidumbres sean más un resultado de nuestro limitado conocimiento del descomunal razonamiento del estagiriano que de la existencia de efectivos problemas en él sospechados. Esto nos guardará para volver con mayor detenimiento más adelante. Por el momento nos detendremos con lo alcanzado (1992).

4 Ibfd., 602. mia [A.C]. 